\title{
Diagnosis and Treatment of Dysentery
}

\section{Shurong Zhong Wei Zhong Chazhen Xia}

Gugang Central Health Center, Liuyang City, Hunan Province, Liuyang, Hunan, 410301, China

\begin{abstract}
Dysentery is a common intestinal infectious disease in summer and autumn. The etiology is mostly from dampness and heat invasion or unclean food, or because of heat greed, excessive cold, resulting in cold and heat inclusion, diet stagnation, heat stagnation and dampness steam, mutual obstruction of gastrointestinal tract, adverse disease. This paper discusses the clinical treatment of dysentery in traditional Chinese medical.
\end{abstract}

\section{Keywords}

dysentery; traditional Chinese medical; dialectics; treatment

\section{痢疾的辨症论治}

钟书荣 钟威 夏茶珍

湖南省汶阳市古港中心卫生院, 中国・湖南汶阳 410301

\section{摘 要}

痢疾多发于夏季、秋季, 是一种常见肠道传染病。病因多由湿热内侵或食不洁食物, 或因热令凉, 过食生冷, 以致寒热夹杂, 饮食停滞，热郁湿蒸，互阻胃肠，逆发本病。论文对痢疾的中医临床治疗手段进行探讨。

\section{关键词}

㾥疾; 中医; 辩症; 治疗

\section{1 引言}

痢疾主症是发热恶寒, 腹痛, 里急后重, 大便脓血。前 人认为 “无积不化㾥” 痢无补法, 主张清理肠胃, 消导积滞, 消除脓血便为主。清代喻昌则提出 “逆流挽舟法” 近代医家 认为这是上策。因本病的产生, 是外有署湿蕴郁, 卫气不疏; 内有积滞蕴热, 表里不和, 寒热交杂, 三焦不畅, 深入血分, 化为脓血, 而成痢疾。用逆流挽舟法治疗痢疾初期, 多以疏 表邪而利气机, 内以化积化积滞而调肠胃, 以表疏热解, 气 机开畅, 热郁自解, 痢亦痊愈。笔者治痢, 师其意而选用蕉 香正气散配葛根芩连汤。佐以药药, 功效甚显。

\section{2 痢疾的治疗原则及分类}

治疗痢疾, 当须解除大便脓血及里急后重, 古人云: “行 血则便胀自愈” “调气则后重自除” 痢疾的脓血便, 是由于

【作者简介】钟书荣（1952-）, 男, 中国湖南汶阳人, 本科 学历, 现任湖南省汶阳市古港中心卫生院中医科副主任医师, 从事中医临床研究。
湿热蕴郁, 伤于血分, 所以用行血的方法, 血行则郁热解除, 脓排则肌肉新生, 便脓自愈。关于用调气解除后重, 是因后 重的机理为气分郁结, 三焦不畅, 湿邪中阻, 故以调气法治 之, 后重病自除, 所谓调气法, 不仅是几味调气药, 而包含 消除气分郁结种种治法，如气分热则凉之则调；若有寒湿用 温化方法亦是调, 治痢疾与治其他疾病一样, 也需审证求因, 辨证施治, 一般可分为湿热痢、寒湿痢、久痢三种。

\section{3 湿热痢的中医治疗}

湿热痢: 署挟湿, 湿热不化, 与肠胃积滞互阻而成。开 始头晕身热, 阵阵恶寒, 腹痛里急后重, 大便滞下不爽, 带 有脓血便, 每日次数较多。舌苔白淢根厚红, 脉多滑数成浮 滑数, 胸中烦闷, 胃不纳, 其主要证治如下。

（1）初起表邪较重, 见寒热头痛, 周身乏力, 腹痛, 大便带有脓血, 里急后重, 舌苔白淢, 脉浮滑数。治疗以疏 表化湿为主, 消化湿热为, 多佐导滞, 用荆防败毒去人参; 芥穗 $6 g$, 防风 $6 g$ 、芫活 $3 g$ 、独活 $3 g$ 、葛根 $10 \mathrm{~g}$ 、黄芩 $9 g$ 、 
黄连 $3 \mathrm{~g}$ 、赤䓁 $6 \mathrm{~g}$ 、焦三仙各 $10 \mathrm{~g}$ 。

（2）偏于热重时, 症见下痢较重, 大便见有脓血, 次 数甚多, 寒热烦泻口干, 小色黄, 舌苔黄质㖓, 脉象数。可 用清化湿热方法, 如葛根芩连汤, 葛根 $10 \mathrm{~g}$ 、黄芩 $12 \mathrm{~g}$ 、黄连 $6 \mathrm{~g}$ 、生甘草 $6 \mathrm{~g}$ 、木香 $6 \mathrm{~g}$ 、焦三仙各 $10 \mathrm{~g}$ 。

(3) 表邪已解, 湿热积滞互阻不化, 舌红苔黄根厚, 身热已解, 腹痛里急后重, 大便带有脓血, 日行 20 次左右, 脉象多滑数有力。可用温苦化湿, 消导和滞法, 如苻药汤加减; 赤药 $10 \mathrm{~g}$ 、白芶 $10 \mathrm{~g}$ 、炒官桂 $3 \mathrm{~g}$ 、葛根 $6 \mathrm{~g}$ 、黄芩 $10 \mathrm{~g}$ 、黄连 $6 \mathrm{~g}$ 、木香 $6 \mathrm{~g}$ 、槟榔 $10 \mathrm{~g}$ 、大黄 $1 \mathrm{~g}$ （冲）。

（4）湿热积滞, 深入血分, 下痢脓血, 赤多白少, 腹 痛后痛, 小舅赤热, 舌红㖓而口干, 脉弦滑急数。用苦坚泄 热法, 仿白头翁汤, 白头翁 $12 \mathrm{~g}$ 、黄芩 $10 \mathrm{~g}$ 、川连 $6 \mathrm{~g}$ 、葛根 $10 \mathrm{~g}$ 、黄柏 $6 \mathrm{~g}$ 、秦皮 $6 \mathrm{~g}$ 、银花 $20 \mathrm{~g}$ 、地榆 $10 \mathrm{~g}$ 、防风 $6 \mathrm{~g}$ 。

（5）湿热灼阴, 热痢较重, 形体削瘘, 干呕不止, 噤 口不能进食, 舌㖓干裂少津, 脉多细数成细弦滑数。当先输 液救津, 再予甘寒育阴, 苦涩折热, 可用开噤散; 易人参 改沙参。沙参 $30 \mathrm{~g}$ 、麦冬 $12 \mathrm{~g}$ 、银花 $20 \mathrm{~g}$ 、赤药 $12 \mathrm{~g}$ 、冬瓜皮 $30 \mathrm{~g}$ 、黄连 $6 \mathrm{~g}$ 、白头翁 $12 \mathrm{~g}$ 、另米汤合牛奶代饮, 以增营养。

\section{4 寒湿痢的中医治疗}

寒湿痢: 痢疾因治疗失误, 或体质过差, 湿从寒化, 或 属素体下焦虚寒, 又因过食生冷, 脾胃阳气受, 升不足, 寒 湿留而不化, 也能发生下痢。其症腹痛多为隐痛, 得暖即舒, 喜按喜温, 舌苔白质淡, 脉象多沉或沉迟微弱等 ${ }^{[1]}$ 。治疗当 温脾暖中, 补气祛寒, 不可用攻消寒泄之品, 其主要证治如下。

（1）寒湿下痢, 腹痛不重, 喜暖喜温, 面色苍白, 四 肢不温, 下痢白多赤少, 腹中隐隐不舒, 白苔白淡润, 脉象 沉迟力弱, 周身疲乏少力, 可用香运温中方法, 药如不换金 正气散，苏叶 $6 \mathrm{~g}$ 、苏梗 $6 \mathrm{~g}$ 、桔枝 $6 \mathrm{~g}$ 、炮姜 $6 \mathrm{~g}$ 、炒官桂 $6 \mathrm{~g}$ 、 苍术 $6 \mathrm{~g}$ 、厚朴 $6 \mathrm{~g}$ 、木香 $6 \mathrm{~g}$ 、白芶 $10 \mathrm{~g}$ 、采甘草 $10 \mathrm{~g}$ 、鸡内金 $10 g_{\circ}$

(2)下元不足, 寒湿伤脾, 署季过食生冷, 腹痛隐隐不休, 下坠后重, 气短, 舌苔白润而淢, 脉象沉迟无力, 大便时带脓血, 不多, 胃中痦满, 不思纳, 当用温运中州法, 少佐消导之品。 方用桂枝 $6 \mathrm{~g}$ 、肉桂粉 $3 \mathrm{~g}$ 、炮姜炭 $6 \mathrm{~g}$ 、木香 $6 \mathrm{~g}$ 、生地黄 $6 \mathrm{~g}$ 、 苍术 $6 \mathrm{~g}$ 、白术 $6 \mathrm{~g}$ 、枳壳 $6 \mathrm{~g}$ 、白冠仁 $2 \mathrm{~g}$ 、焦谷芽 $10 \mathrm{~g}$ 、焦麦 芽 $10 \mathrm{~g}$ 、鸡内金 $6 \mathrm{~g}$ 。

\section{5 久痢的中医治疗}

久痢: 久痢原因很多, 除了误治、失治, 亦有因病人不 与医生配合所致。治疗方法必须详审病情, 随证施治。其主 要证治如下。

痢疾经久不愈, 正气大伤, 湿热不清, 饮食失当, 运化 难以恢复正常, 舌苔根厚而淢, 脉多滑数而力弱。治以升阳 运化, 调和脾胃, 方用香砂枳术丸合保和丸化裁; 升麻 $6 \mathrm{~g}$ 葛根 $6 \mathrm{~g}$ 、炒官桂 $3 \mathrm{~g}$ 、炮姜 $3 \mathrm{~g}$ 、木香 $6 \mathrm{~g}$ 、砂仁 $2 \mathrm{~g}$ 、枳壳 $6 \mathrm{~g}$ 、 炒白术 $9 \mathrm{~g}$ 、焦三仙 $6 \mathrm{~g}$ 。

久痢正气大伤, 脾胃运化力弱, 舌淡苔白, 脉象软弱无力, 可见扶脾开运为务, 少佐补正。用香砂六君子汤加味, 升麻 $6 \mathrm{~g}$ 、柴胡 $6 \mathrm{~g}$ 、荆芥穗炭 $6 \mathrm{~g}$ 、党参 $10 \mathrm{~g}$ 、砂仁 $3 \mathrm{~g}$ 、茯苓 $10 \mathrm{~g}$ 、 白术 $10 \mathrm{~g}$ 、山药 $15 \mathrm{~g}$ 、冬瓜皮 $15 \mathrm{~g}$ 。

高年久痢, 正气难以恢复, 时时汗出, 汗后形寒, 便则 脱肚, 四肢逆冷, 舌胖苔白, 脉沉细小弱, 可用温养升运, 少佐固涩, 仿真人养脏汤方意, 党参 $10 \mathrm{~g}$ 、淡附片 $10 \mathrm{~g}$ 、黄芪 $20 \mathrm{~g}$ 、升麻 $10 \mathrm{~g}$ 、柴胡 $6 \mathrm{~g}$ 、炮姜 $6 \mathrm{~g}$ 、炒官桂 $6 \mathrm{~g}$ 、干姜 $6 \mathrm{~g}$ 、河 子肉 $6 \mathrm{~g}$ 、苂实 $10 \mathrm{~g}$ 、茯苓 $10 \mathrm{~g}$ 。

\section{6 痢疾辩症治疗中的另外分型}

痢疾在辩证治疗中还可以分为疫毒痢, 寒温痢, 虚寒痢, 休息痢，噤口痢。

\section{1 疫毒痢}

疫毒痢需要使用清热解毒凉血的方法治疗, 主要选择的 方药为白头翁汤 ( 《伤寒论》) 以及䓎药汤 ( 《素问病机气 宜保命集》) 进行加减治疗。使用药物有黄芩, 白头翁, 秦皮, 黄连, 药药, 当归, 槟榔, 木香, 山楂, 连翘, 银花, 地榆, 鲜马齿苋。如果患者发生高热神昏的情况, 属于热毒深人营血, 需要添加 30 60g 的水牛角, 另外添加 1 支紫雪散或者 1 丸安 宫牛黄丸或局方至宝丹，化服，每天使用 2 次。还可以服用 40 60ml 的清开灵，加入 $500 \mathrm{ml} 5 \%$ 的葡萄糖盐水，每天使用 2 次, 具有开项醒神, 清营凉血的作用 ${ }^{[2]}$ 。

\section{2 寒温痢}

寒温痢需要使用温补脾肾的方法治疗, 主要使用方药为 真人养脏汤（《太平惠民和剂局方》）。使用药物有肉豆冦、 党参、肉桂、木香、诃子、白术、罂粟壳、灶心土、甘草、白药、 干姜。如果患者出现明显畏寒肢冷的情况, 可以添加附子, 
吴莫具有温肾壮阳的作用。对于中气下陷, 滑肠脱肛的患者, 需要将木香去掉, 添加黄花, 具有升麻益气的作用。对于大 便不爽, 挟积滞的患者, 将罂栗壳, 诃子去掉, 添加槟榔, 山楂进行行气导滞。

\section{3 虚寒痢}

虚寒痢在发病后会出现时轻时重, 病程较长, 带有白凉, 下痢稀薄, 便下不畅, 小腹隐痛, 甚至滑脱不禁, 畏寒肢冷, 身倦乏力, 口淡不渴, 食少神疲, 苔薄白, 舌质淡, 脉细弱。 在治疗中也需要使用温补脾肾的药物。主要使用方药为真人 养脏汤 (《太平惠民和剂局方》)。使用药物有肉豆冦、党参、 肉桂、木香、诃子、白术、罂粟壳、灶心土、甘草、白药、干姜。

\section{4 休息痢}

休息痢在病情发作时使用连理汤 (《张氏医通》) 加减 治疗。使用药物有炮姜、多甘草、黄连、党参、白术、获苓、 黄柏、五倍子、苦参、当归、煨木香。如患者出现痢疾休止, 可以使用香砂六君子丸, 添加山楂、木香、黄连治疗, 具有
健脾益气, 巩固疗效的作用。如患者肠中寒积不化, 脾阳不振, 下痢白冻, 遇寒即发, 舌质淡苔白脉沉, 倦急少食。可以使 用温脾汤加减治疗, 具有消食导滞, 温中散寒的作用。

\section{5 噤口痢}

噤口痢在治疗中使用苦辛通降, 泄热和胃的方法治疗, 使用开噤散 (《医学心悟》) 加减治疗。使用药物有石菖蒲、 陈皮、黄连、获苓、荷叶蒂、半夏、陈仓末、大黄。如患者 出现虚证, 使用参苓白术散 (《太平惠民平剂局方》) 或者 香砂六君子汤 (《时方歌括》) 加减治疗, 使用药物有砂仁、 白术、木香、党参、甘草、获苓、扁豆、生薏药仁、陈皮、 淮山药、清半夏。

\section{参考文献}

[1] 戴毓丽. 浅谈中医对痢疾的诊断、鉴别与治疗 [J]. 世界最新医学 信息文摘 (电子版),2013(04):405-406.

[2] 杨生科. 中医治疗小儿㾥疾四则 [A]. 中医杂志 [C]. 中国中医药学 会, 2000 . 